\title{
Integrating Structure and Function in Conceptualizing and Assessing Pathological Traits
}

\author{
Aidan G.C. Wright Aleksandra Kaurin \\ Department of Psychology, University of Pittsburgh, Pittsburgh, PA, USA
}

\section{Keywords}

Personality pathology - Personality traits - Structure .

Function · Contextualized processes

\begin{abstract}
The Diagnostic and Statistical Manual of Mental Disorders' (5th Edition) Alternative Model of Personality Disorders includes a dimensional trait model to describe individual differences in the manifestation of personality pathology. Empirically derived quantitative trait models of psychopathology address many of the structural problems of classical diagnostic schemes (e.g., nonbinary distributions, excessive comorbidity, and diagnostic heterogeneity). However, they are largely based on the structure of individual differences in the manifestation of psychopathology. In contrast, clinical theories of personality disorder, which are the foundation of intervention efforts, are based on the function of maladaptive behavior. This distinction is akin to the difference between morphology and physiology in the broader biological sciences. A structure-function divide in the focus of empirical and clinical work contributes to a lack of integration and difficulties with translation. Here we discuss this tension and argue for the need to bridge this divide and adopt research
\end{abstract}

(c) 2020 S. Karger AG, Base

www.karger.com/psp

Karger ${ }^{\prime}=$ efforts that integrate structure and function of personality traits. Specifically, we suggest that between-person structure identifies the principal domains of functioning, but to understand dysfunction personality must be conceptualized and studied as an ensemble of contextualized dynamic processes.

(c) 2020 S. Karger AG, Basel

\section{Integrating Structure and Function in Conceptualizing and Assessing Pathological Traits}

Personality pathology occupies a challenging position in clinical research and practice. Unlike primarily affective syndromes that are often experienced as separate from the individual (i.e., egodystonic), personality pathology refers to difficulties in the most central elements of our identities - ingrained in enduring habits of thought, feeling, behavior, and how we think of ourselves (i.e., egosyntonic). As such, personality pathology is essential to who we are as persons and, when severe, it is pervasive, persistent, and difficult to characterize and treat. It often undergirds common problems like depression and anxiety, and without careful evaluation these core functional 
patterns are downplayed at best and overlooked at worst. In spite of, or perhaps because of, its fundamental and pervasive nature, modern psychiatric nosology has struggled to adequately describe and define personality pathology. For the past 40 years, official diagnostic nosologies, like the Diagnostic and Statistical Manual of Mental Disorders (DSM), have organized personality pathology using a syndrome model with $(\sim 10)$ discrete polythetic categories. Despite some notable successes in treatment development for and changing public perceptions of borderline personality disorder, the syndromal approach to describing, studying, and treating personality pathology has proven to have limited clinical utility and resulted in a stagnating, if not degenerating, research program.

By the time preparation of the DSM-5 [1] began, it had become apparent that by merging heterogeneous and fuzzy symptom sets with diagnostic cutoffs the model fails to faithfully represent clinical or empirical reality in a sufficiently meaningful way [2]. Thus, an effort was made to fundamentally revise the description and diagnosis of personality pathology. What ultimately came to be known as the Alternative DSM-5 Model for Personality Disorders (AMPD) sought to combine a detailed core definition of personality pathology largely adopted from clinical observation and theory, which emphasized impairments in self and interpersonal functioning (Criterion A), with a dimensional trait model established by psychometric procedures, which emphasized individual differences in how these impairments manifest (Criterion B). For a variety of reasons, some putatively scientific, some decidedly practical, and some undoubtedly politi$\mathrm{cal}$, this model was not adopted for the main section of the manual (Section 2), and instead was relegated to the Emerging Models and Measures section (Section 3) at the back of the book [3].

In this brief review, we focus on Criterion B and the value and challenges of incorporating a psychometrically derived personality trait model as part of a psychiatric diagnostic framework. There are well-established advantages of a dimensional trait model that we review below, yet despite these there has been and continues to be staunch antagonism towards this approach from some corners of the field. Our goal is not to further unmitigated argument in favor of dimensional traits, and instead, in a spirit of consilience, we offer an interpretation of what we perceive as the major opposition against such a model with a view towards proposing steps to integrate traits with longstanding clinical perspectives on personality pathology that emphasize failures in adaptive personality functioning. These include maintaining a coherent sense of self and mutually rewarding relationships, regulating affect, and selecting and pursuing goal-directed behavior.

The motivation for moving to what ultimately became the AMPD was to address the problematic features of personality disorder diagnosis in order to advance clinical practice and reinvigorate research into its etiology, maintenance, and treatment. The key pitfalls of the current (or any) discrete categorical model of personality syndromes include the scientific imprecision and clinical inutility of these categories, reflected in the high heterogeneity of those with the same diagnosis $[4,5]$, high covariation among diagnoses [6] with severe cases often described in terms of multiple personality disorder diagnoses, and the fact that many individuals with apparent personality pathology do not match any diagnoses' criteria, resulting in the overreliance on unspecified diagnoses [7]. Beyond these semantic issues, the current diagnostic cutoffs for number of criteria are deceptively precise ${ }^{1}$ with respect to distinguishing between those with and without significant clinical impairments [8,9]. The downstream effects of such a poorly calibrated diagnostic scheme include inactive or declining research programs dedicated to personality pathology and that treatment approaches have been developed for only a minority of these categories. As it stands now, the vast majority of diagnosis-based research is focused on borderline personality disorder, with little attention focused on other diagnoses.

A multidimensional trait model had long been proposed as a viable alternative because it addressed the fundamental imprecision and many associated problems of a syndrome model of personality disorder [10-12]. In basic personality science, contemporary trait models were derived empirically from the patterns of covariation in natural language descriptors of important individual differences in characteristic patterns of thinking, feeling, and behaving [13]. By extension, the same methods, when applied to clinical descriptors of maladaptive personality in the form of diagnoses, symptom counts, individual symptoms, or clinical scales result in models with a similar number of broad dimensions [14-16]. The trait model incorporated in the AMPD includes 25 lower-order scales and 5 higher-order domains. The process by which

\footnotetext{
These cutoffs are often referred to as "arbitrary" but, as Peter Zachar noted in personal communication, this is probably something of a straw man argument and they are better referred to as "deceptively precise." They are not arbitrary because they are reasonably severe and most would agree that those meeting this threshold are significantly impaired. However, they are problematic in that they suggest a precise boundary that does not exist.
} 
this model was derived involved identifying and generating the universe of content needed to faithfully capture personality pathology, developing individual scales for each construct, and submitting self- or clinician report versions of these scales to factor analysis $[17,18]$. The DSM-5 pathological trait model has been highly generative leading up to and since its publication [19-21], and the International Classification of Disease - 11th Edition [22] has adopted a similar scheme for the definition and diagnosis of personality pathology.

Whereas the pattern of strong covariation among symptoms across diagnoses is problematic when dealing with putatively distinct categories, it is expected in a hierarchical trait model where signs, symptoms, and diagnostic constructs are undergirded by a set of shared processes. Psychometrically derived trait models establish dimensionsthatdescribedomains ofpersonalitydysfunction and therefore are understood to be continuously distributed, with little evidence for discernable discontinuities [23-26]. The continuous nature of dimensional traits more clearly conveys to researchers and practitioners that any agreed-upon cutoff is largely in the service of practical utility, but it is not intended to reflect of the state of nature. They can also better accommodate multiple cutoff points consistent with a clinical staging model. In addition to addressing the limitations of imprecision described above, this model provides other notable benefits, like linking to models of basic personality (e.g., the 5-factor model among others) $[27,28]$ and psychopathology writ large (e.g., the Hierarchical Taxonomy of Psychopathology; HiTOP) [29, 30]. This results in greater scientific synthesis, providing a shared understanding of normative and maladaptive functioning. It further makes the many additional findings of basic personality science clinically relevant and places maladaptive personality functioning as centrally relevant for understanding all of psychopathology.

However, shifting to a dimensional trait model has been met with skepticism and even derision by many prominent scholars) [31-33]. The concerns raised take on varied forms, but at their core they involve a sincere worry that a trait-based model will do violence to the clinical utility of personality disorder diagnoses and erase years of hard-won knowledge and painstakingly accrued gains in the treatment of severe forms of personality disorder [34]. The essence of this perspective is perhaps best summarized by Gunderson [p. 120 in 31]: “The existing types arose out of clinical observations of the recurrence of clinical problems within therapies - problems that were also recurrent elsewhere in their patient's lives ...
This is the same empirical base upon which most of medicine has developed classifications of most illnesses ... No scientific model ... can claim comparable clinical utility. The proposed architecture can claim to be more scientific, but we should not easily back away from any nosological system that is based on the recurrent behavioral patterns observed by multiple generations of clinicians on actual patients who are seeking help."

We feel it is important to note that these sentiments are not limited to the AMPD (and by extension the ICD11) trait model and appear to generalize to more extensive revolutionary models of psychopathology writ large. As Weinberger et al. [p. 1,161 in 35] succinctly stated in reference to the NIMH Research Domain Criteria: "Do we need to replace categorical with dimensional diagnoses to make progress in psychiatry research? No."

But what is at the root of this skepticism? Why are trait models, despite their undeniable empirical superiority and potential to promote advances in clinical utility [3640], viewed so pessimistically by some in the field? What we understand Gunderson [31] and others to be saying is that from the perspective of the consulting room, traitbased clinical formulation rings "tinny" and lacks the timbre or resonance of the clinical description of legacy constructs like borderline, histrionic, or narcissistic personality disorders, to name a few. As Zachar [8] argued, kind concepts are practically useful ways of integrating information. They are like models that represent certain important aspects of a case but not all features. When faced with the complexity of personality pathology with the demands of a busy clinical practice, it is easy to see how this form of pragmatism is useful despite the obvious difficulties it poses in empirical studies.

Ultimately, however, the advocates for quantitative dimensional models and clinically constructed practical kinds are talking past each other if not speaking different languages. Indeed, one is often talking the language of statistical procedures, and the other is talking about sitting in the room with a patient in all their challenging complexity. In a nutshell [p. 397 in 41]: "The clinician knows he (SIC) is dealing with process. He (SIC) cannot help but remain unimpressed with statistical procedures and results which are applied to observations made at comparatively isolated points in time, and which do not tell him something of what has been happening along the way."

The question then becomes: How do we translate each of these perspectives, the statistical/empirical and the clinical/pragmatic, into a lingua franca of personality pathology that both parties feel comfortable speaking? 
The inherent tension in the field relates to what we will term the structural and functional divide [42, 43]. Being able to make translation across this divide, or integrating the 2 parts into a coherent whole, would be useful for resolving concerns with dimensional models of psychopathology while placing nosological models on solid empirical footing. Analogizing to biology, structure is akin to morphology, whereas function is akin to physiology. Knowing that there are distinct tissue types is useful for recognizing different organs (e.g., brain, liver, kidney, heart, and lungs), but structural models are static. What function each of those organs serves, and how they accomplish it, is rarely immediately and fully obvious from the differences in structures. With functional models we develop an understanding of what is actually happening they are dynamic. In psychopathology nosology, structure has been the focus of empirical research, it has emphasized static relationships (e.g., individual differences), and it has thus far been descriptive in nature. In contrast, function (or dysfunction as it may be) is the focus of clinical theories, it emphasizes dynamic processes of pathogenesis and perpetuation (i.e., mechanisms), and it is ultimately explanatory in nature. Others have argued for this same basic point, framing it as integrating structural and dynamic perspectives on personality and its pathology [44-47].

To illustrate, consider pathological narcissism (or, more narrowly, narcissistic personality disorder) from each perspective. From a structural perspective, narcissism might be understood as reflecting maladaptive trait antagonism or more specifically described as elevated grandiosity and attention seeking [1]. From a functional perspective, these same pathological features might be described in terms of relationships exiting to serve selfesteem regulation and goal setting that is based on gaining approval from others. As another example, consider borderline personality disorder. From a trait-based perspective, borderline personality disorder is captured in large part by emotional lability, impulsivity, and hostility. A functional perspective might emphasize an underdeveloped sense of identity and insecure attachment that leave the individual vulnerable to dramatic shifts of mood and behavior poorly calibrated to the situation that serve to gratify overvalued goals or ward off fears of abandonment.

The trait-based approach provides a perfectly adequate description of the average behavior of an individual diagnosed with narcissistic or borderline personality disorder, but it fails to offer an explanation for how and why it occurs and what the maintenance (i.e., reinforcement) mechanisms may be. As such the trait-based mod- el makes it difficult to know where or how to intervene and is therefore clinically uncompelling when considered in isolation. Indeed, anyone who only looks to the structural model's traits for the personality disorder syndromes in the AMPD would see a list of traits without having any idea of how or why these fit together. The trait model for each personality disorder construct presupposes some knowledge about the functional clinical concept. The trait model is informative, but it can be much more so if one also possesses an understanding of the functional clinical processes that are defining of personality pathology. Ideally both perspectives would inform each other and coevolve.

Integrating structure and function could help bridge the scientific-clinical divide, but doing so will require both conceptual and empirical work. We must not dismiss longstanding clinical observation and wisdom, and at the same time we should question and improve its organization in diagnostic nosologies. Quantitative statistical procedures can help to identify key structural elements of human behavior and provide incremental validity to functional clinical models. We see the following as guiding principles for these efforts:

Good description is necessary for good explanation.

The same structural model should organize adaptive and maladaptive functioning.

Understanding function requires studying contextually-sensitive within-person processes.

There is a difference between disorder and diagnosis.

We consider each of these principles in turn, although they are fundamentally interlocking and reciprocally informative.

First, without good description explanation is unachievable. This is a matter of construct validity. Without valid constructs there is little to be learned about underlying mechanistic processes. This is perhaps most evident in case control studies of personality disorder diagnoses. Because the diagnoses themselves are heterogeneous, and severe patients often have a good deal of additional pathology, it is unclear what is driving any differences between groups. Appreciation for and concern over this issue is what drives the need to move away from the current categorical model of personality disorder diagnosis. A quantitative empirical approach, as has been used to identify a hierarchy of personality traits, is intended to generate "good descriptions" of valid constructs that will fuel mechanistic research [48]. As descriptions, they serve to identify the domains of functioning that must be understood individually and as they interact within a person as a dynamical system over time. 
Second, the same structure should organize function and dysfunction. It should be neither surprising nor controversial that the domains identified by structural analyses of dysfunction align with the major domains identified by structural analyses of normative functioning (i.e., basic personality traits) $[28,49,50]$ - it should be axiomatic. In much the same way that the biologist and oncologist both have the same fundamental understanding of the parts and inner working of a cell, so too should personality psychologists and clinicians have the same understanding of personality's structure and function. Structural models of personality traits, like the interpersonal circumplex [49] or the five-factor model, identify functional domains and personality pathology needs to identify when and why there is dysfunction in those units. To illustrate, though sticking to the broad domain level for considerations of space, basic personality domains describe individual differences in regulation of interpersonal relating (extraversion and agreeableness), affect (extraversion and neuroticism), goal-directed behavior (Conscientiousness), and cognition/intellectual pursuit (openness). The AMPD pathological personality traits similarly describe individual differences in the dysfunction of regulation of interpersonal relating (antagonism and detachment), affect (negative affectivity and detachment), goal-directed behavior (disinhibition), and cognition/intellectual pursuit (psychoticism). Recognizing that the content of basic and maladaptive personality traits align further explains why personality and its pathology covary strongly with clinical syndromes across traditional diagnostic boundaries as reflected in models like HiTOP [50-53].

Third, understanding function requires studying contextually sensitive within-person processes in addition to modeling individual differences in a population as structural models do. Clinical features of personality pathology, as codified in diagnostic criteria of the current categories, emphasize not only the average levels of behavior (e.g., high levels of impulsive behavior), but also the contextual nature of key symptoms, or at least it is clear how this is implied ${ }^{2}$ [54]. For instance, it is the perceptions of abandonment that drive dramatic efforts to avoid it in borderline pathology. Basic personality science is also informative here. After a century of studying the structure of personality, personality science has now shifted direction and begun to understand traits as emerging from underlying processes that are the core of what we are truly

\footnotetext{
2 Arguably describing behavior as impulsive also implies that the behavior is contextually inappropriate.
}

interested in when we wish to know a person. Ambulatory assessment studies $[55,56]$ have revealed that the Big-5 traits are not static monoliths, immutable across time and circumstance, but rather may better understood as "density distributions" of states with a discernible set point around which behavior varies as the situation demands. This opens the door to relevant functional theories of personality that seek to explain the processes that give rise to what are recognized as traits, including perceptual, affective, situational selection, and motivational/ goal components [57-59].

The dynamic processes of trait-relevant behavior activated and enlisted to serve some purpose goes back to the early observation of Allport [60] that "personality is and personality does." By extension, when it comes to personality pathology, personality is not doing what it is supposed to do. This helps frame a nonspecific functional definition of personality pathology, in that maladaptive personality functioning occurs when an individual's behavior consistently fails to meet the demands of normative situations. This might be due to any number of specific reasons, including such things as poorly understood expectations, misperceptions, rigid application of rules across diverse situations, and behavioral excesses or inhibitions that under- or overshoot the situational demands, among others. Further, situations need not be defined exclusively as the external setting within which the individual finds him- or herself but can also include the intrapersonal context through an individual's capacity for mental representation, construal, and recall.

In order to begin to understand maladaptation as a functional process we must study it as such, which means involving intensive repeated measures over time and circumstance. We believe the most fruitful direction for research on personality pathology is to adopt this very same perspective and invest heavily in intensive longitudinal research designs, referred to variably as ambulatory assessment, ecological momentary assessment, or experience sampling, that assess behavior and context repeatedly over time [61-63]. Indeed, over the past 10-15 years this type of work has been increasingly used in psychopathology generally [64] and personality pathology specifically [65]. Early findings have begun to provide systematic empirical support for longstanding clinical observations, such as the fact that individuals diagnosed with borderline personality are more unstable in affect and interpersonal behavior than community or depressed controls $[66,67]$. Or, for example, that borderline pathology is associated with stronger negative affect in situations where others are perceived as less affiliative [68, 69], 
whereas narcissism is associated with stronger negative affect in situations where others are perceived as more dominant [70]. However, this work has often been centered on traditional diagnoses with all the limitations those entail.

Thus, revisiting the preceding point, it is not sufficient to adopt intensive longitudinal assessment in naturalistic settings designs; it must be organized around valid constructs, such as the AMPD domains. We have recently begun following this same path but using pathological personality traits instead of the normative Big-5. For instance, Wright and Simms [65] followed individuals diagnosed with any DSM-IV personality disorder for 100 days, using daily diaries to sample daily manifestations of pathological personality traits derived from the DSM-5 AMPD (i.e., negative affectivity, detachment, antagonism, disinhibition, and psychoticism). Results showed that while individual differences in these daily expressions of personality pathology were associated with individual differences in traits using standard dispositional self-report assessments they were also highly variable across days, such that half the total variability was associated with daily fluctuations. Additional work with these same data [71] has shown that the structure of individual differences in these daily manifestations, as well as the structure of how the daily fluctuations covary, both follow a hierarchical structure that is consistent with structural models of traits [27] and psychopathology more broadly [29]. This lays down the initial support beams for the bridge between structure and function. Ongoing work has sought to expand the measurement tools available for the daily capture of fluctuations in personality pathology to extend this line of inquiry [72].

Fourth, a diagnosis is not the same thing as the disorder. A diagnosis may have practical utility for some clinical purposes, but it should not be confused with a selfcontained natural entity. As psychopathologists, we need to prioritize understanding the mechanisms of personality pathology, not the implications of pragmatically defined cutoffs (either within or between diagnoses). Personality disorder diagnoses are not useful for mechanistic research because they are rife with these arbitrary decisions. The US National Institute of Mental Health recognized this, and this realization was the impetus for eschewing DSM diagnosis-based research in favor of the Research Domain Criteria [73]. As obvious as this may seem, this point bears revisiting and elaboration because the same issue will resurface when shifting to any novel or trait-based system of organizing personality pathology. Some form of diagnostic rules or cutoffs will be neces- sary to inform epidemiological studies and clinical practice. At the same time, these must not be confused with the pathology they intend to signal. As many have previously done, we can draw comparisons with blood pressure. This, too, is a dimensional and dynamic system that has implications for healthy functioning and pathology. Cardiology has successfully established cutoffs for stages of hypertension (i.e., rarely is clinical utility best served with a single cutoff) that serve as guidelines for treatment recommendations (watching, lifestyle changes, medication, etc.), ideally based on research that indicates levels of expected harm. However, these cutoffs or stages are not the disorder; the disorder are the mechanisms that conduce toward a higher blood pressure and may or may not be distributed along a similar dimension. Therefore, although clinical cutoffs may be useful for applied research on prognosis or treatment response, they are insufficient and possibly unhelpful for studying mechanisms.

We believe heeding the 4 principles outlined above will provide a fruitful way forward for personality psychopathologists that balances the concerns of the major scientific and practitioner stakeholders. With that said, several thorny issues remain. One of the most salient is the need for a theoretically driven functional model to identify and organize the dynamic processes of highest interest. We have decided to remain agnostic and not further any particular model here, and we see several that might be fruitful. The most promising are those that already seek to integrate structure and functioning, albeit emphasizing different foci. For instance, some, such as the Harkness et al.'s [74] "review of systems" approach, define functioning in evolutionarily adaptive terms. DeYoung [58] has a similar emphasis and draws on cybernetic theory to account for functional processes [75]. Others, such as the model of Depue and Lenzenweger [76, 77], have based their account at the level of neurobehavioral functioning. Contemporary interpersonal theory $[46,47]$ is promising in that it spans levels of functioning and provides a detailed account of the motivations and behavioral processes that are normative. These are but a subset of potentially fruitful approaches, and likely each will be able to contribute important insights moving forward.

Further, any new approach to framing personality pathology must contend with the fact that establishing clinically actionable diagnostic thresholds or determining "caseness" is a thorny challenge for any system. In large part this is due to the difficulty of defining disorder. Indeed, clinical pragmatism may also be reflective of the fact that "there is no set of properties that all psychiatric disorders share, and that distinguish them from nondisor- 
ders" [p. 125 in 8]. Some have referenced the sorites paradox to classifications based on indiscriminate diagnostic cutoffs or fuzzy terms such as "abnormal" or "pathological," emphasizing that many of the clinical properties that we attribute to people are imprecise, even arbitrary [78, $79]^{3}$. In fact, dimensional definitions of psychopathology, such as those implied by the AMPD and that we further here, will also be plagued by vagueness, particularly because nonarbitrary cutoff points between normal and abnormal functioning are unlikely to emerge in any welldefined fashion [80]. Instead, any threshold is likely to be located in a region of transition that does not solve but merely circumvents the issue [81]. In analogy to the sorites paradox, where it is difficult to determine when successively smaller piles of sand may be called heaps, in personality pathology comparable but weaker gradual transitions on dimensions may still produce clinically relevant impairment. What becomes evident is that not all difficulties (e.g., nonbinary distributions, excessive comorbidity, and diagnostic heterogeneity) emerge from formalization of personality disorders. By default, there is uncertainty in the experience of distress, impairment, or personal functioning, in developing a disorder, and in becoming a heap [81]. The important thing is to realize that any threshold defined by clinical necessity (just like hypertension) is not the disorder but a practical decision guided by normative considerations. They simply guide us through "the variety of the decisions we make in order to classify an indeterminate world" [p. 289 in 82].

In the spirit of conciliation, we have argued that contemporary quantitative dimensional models and longstanding clinical observation and theory must be alloyed to move personality pathology forward. The AMPD is an important step in this direction. We recognize that a key critique of the AMPD is that it is too intricate, with little clinical utility. Admittedly, when compared to the 10 (more or less) clear-cut syndrome groups, it could be argued that, in the pursuit of increasing diagnostic reliability, the system loses its meaning in a cloud of heterogeneity. However, we believe that, if used in the spirit of clinical functionalism, the AMPD will clarify diagnoses of personality disorders and better integrate them into clinical practice to extend and improve treatment. As we propose, by understanding traits as ensembles of contextual-

\footnotetext{
3 The paradox describes the situation where if you subtract one grain of sand from a heap it is still a heap. This suggests that one grain of sand does not distinguish a heap from a nonheap. If, however, you repeat this enough times, there will only be scattered grains of sand left. It will still be considered as a heap because the removal of no single grain of sand could determine whether or not something is a heap [81].
}

ized dynamic processes they provide a mechanistic view on personality pathology in action. They also offer an enhanced focus on idiosyncratic factors that may maintain and potentially exacerbate each individual's case without rushing to establish pragmatic, imprecise categories that (structurally) equalize disorder and diagnosis. Ambulatory assessment methods, designed around structurally validated components, offer a tractable way forward for this type of "traits as contextualized dynamic processes" research. Finally, there is a need for fully elaborated functional models to give life to the dynamic processes and we noted several theoretic frameworks that are likely to lead this effort.

\section{Acknowledgement}

We wish to thank Christopher Hopwood and Peter Zachar for helpful critical comments on a prior draft that improved the final version of this work - any remaining limitations are our own.

\section{Disclosure Statement}

Neither of the authors have any conflict of interests to declare.

\section{Funding Sources}

This work was not directly supported by any funding agency.

\section{Author Contributions}

Both of the authors contributed to the conceptualization, drafting, and revision of this paper.

\section{References}

1 American Psychiatric Association. Diagnostic and statistical manual of mental disorders. 5th ed. Washington: APA; 2013.

2 Krueger RF, Skodol AE, Livesley WJ, Shrout PE, Huang Y. Synthesizing dimensional and categorical approaches to personality disorders: refining the research agenda for DSM-V Axis II. Int J Methods Psychiatr Res. 2007; 16(S1 Suppl 1):S65-73.

3 Zachar P, Krueger RF, Kendler KS. Personality disorder in DSM-5: an oral history. Psychol Med. 2016 Jan;46(1):1-10.

4 Lenzenweger MF, Clarkin JF, Yeomans FE, Kernberg OF, Levy KN. Refining the borderline personality disorder phenotype through finite mixture modeling: implications for classification. J Pers Disord. 2008 Aug;22(4): 313-31. 
5 Wright AG, Hallquist MN, Morse JQ, Scott LN, Stepp SD, Nolf KA, et al. Clarifying interpersonal heterogeneity in borderline personality disorder using latent mixture modeling. J Pers Disord. 2013 Apr;27(2):125-43.

6 Lilienfeld SO, Waldman ID, Israel AC. A critical examination of the use of the term and concept of comorbidity in psychopathology research. Clin Psychol Sci Pract. 1994;1(1): 71-83.

7 Verheul R, Widiger TA. A meta-analysis of the prevalence and usage of the personality disorder not otherwise specified (PDNOS) diagnosis. J Pers Disord. 2004 Aug; 18(4):309-19.

8 Zachar P. A Metaphysics of Psychopathology. Cambridge (MA): The MIT Press; 2014. https://doi.org/10.7551/mitpress/ 9780262027045.001.0001.

9 Zimmerman M, Chelminski I, Young D, Dalrymple K, Martinez J. Does the presence of one feature of borderline personality disorder have clinical significance? Implications for dimensional ratings of personality disorders. J Clin Psychiatry. 2012 Jan;73(1):8-12.

10 Clark LA. Assessment and diagnosis of personality disorder: perennial issues and an emerging reconceptualization. Annu Rev Psychol. 2007;58(1):227-57.

11 Widiger TA, Trull TJ. Plate tectonics in the classification of personality disorder: shifting to a dimensional model. Am Psychol. 2007 Feb-Mar;62(2):71-83.

12 Hopwood CJ, Kotov R, Krueger RF, Watson D, Widiger TA, Althoff RR, et al. The time has come for dimensional personality disorder diagnosis. Pers Ment Health. 2018 Feb;12(1):82-6.

13 Wright AG. Factor analytic support for the five-factor model. In: Widiger TA, editor. Oxford handbook of the five-factor model. Oxford, UK: Oxford University Press; 2017. pp. 217-42.

14 Wright AG. The current state and future of factor analysis in personality disorder research. Pers Disord. 2017 Jan;8(1):14-25.

15 Wright AG, Zimmermann J. At the nexus of science and practice: Answering basic clinical questions in personality disorder assessment and diagnosis with quantitative modeling techniques. In: Huprich S, editor. Personality disorders: Toward theoretical and empirical integration in diagnosis and assessment. Washington (DC): American Psychological Association; 2015. pp. 109-44.

16 Markon KE, Krueger RF, Watson D. Delineating the structure of normal and abnormal personality: an integrative hierarchical approach. J Pers Soc Psychol. 2005 Jan;88(1): 139-57.

17 Krueger RF, Derringer J, Markon KE, Watson D, Skodol AE. Initial construction of a maladaptive personality trait model and inventory for DSM-5. Psychol Med. 2012 Sep;42(9): 1879-90.

18 Morey LC, Krueger RF, Skodol AE. The hierarchical structure of clinician ratings of proposed DSM-5 pathological personality traits. J Abnorm Psychol. 2013 Aug;122(3):836-41.
19 Al-Dajani N, Gralnick TM, Bagby RM. A psychometric review of the Personality Inventory for DSM-5 (PID-5): current status and future directions. J Pers Assess. 2016;98(1):62-81.

20 Krueger RF, Markon KE. The role of the DSM-5 personality trait model in moving toward a quantitative and empirically based approach to classifying personality and psychopathology. Annu Rev Clin Psychol. 2014; 10(1):477-501.

21 Waugh MH, Hopwood CJ, Krueger RF, Morey LC, Pincus AL, Wright AG. Psychological assessment with the DSM-5 Alternative Model for personality disorders: tradition and innovation. Prof Psychol Res Pr. 2017 Apr; 48(2):79-89.

22 World Health Organization. International statistical classification of diseases and related health problems (11th ed). 2019. Available from: https://icd.who.int/.

23 Aslinger EN, Manuck SB, Pilkonis PA, Simms LJ, Wright AG. Narcissist or narcissistic? Evaluation of the latent structure of narcissistic personality disorder. J Abnorm Psychol. 2018 Jul;127(5):496-502.

24 Haslam N, Holland E, Kuppens P. Categories versus dimensions in personality and psychopathology: a quantitative review of taxometric research. Psychol Med. 2012 May;42(5):903-20.

25 Wendt LP, Wright AG, Pilkonis PA, Nolte T, Fonagy $\mathrm{P}$, Montague PR, et al. The latent structure of interpersonal problems: validity of dimensional, categorical, and hybrid models. J Abnorm Psychol. 2019 Nov;128(8):823-39.

26 Wright AG, Krueger RF, Hobbs MJ, Markon KE, Eaton NR, Slade T. The structure of psychopathology: toward an expanded quantitative empirical model. J Abnorm Psychol. 2013 Feb;122(1):281-94.

27 Wright AG, Thomas KM, Hopwood CJ, Markon KE, Pincus AL, Krueger RF. The hierarchical structure of DSM-5 pathological personality traits. J Abnorm Psychol. 2012 Nov; 121(4):951-7.

28 Wright AG, Simms LJ. On the structure of personality disorder traits: conjoint analyses of the CAT-PD, PID-5, and NEO-PI-3 trait models. Pers Disord. 2014 Jan;5(1):43-54.

29 Kotov R, Krueger RF, Watson D, Achenbach TM, Althoff RR, Bagby RM, et al. The Hierarchical Taxonomy of Psychopathology (HiTOP): a dimensional alternative to traditional nosologies. J Abnorm Psychol. 2017 May; 126(4):454-77.

30 Wright AG, Simms LJ. A metastructural model of mental disorders and pathological personality traits. Psychol Med. 2015 Aug; 45(11):2309-19.

31 Gunderson JG. Commentary on "Personality traits and the classification of mental disorders: toward a more complete integration in DSM-5 and an empirical model of psychopathology". Pers Disord. 2010 Apr;1(2):119-22.

32 Meehan KB, Clarkin JF. A critical evaluation of moving toward a trait system for personality disorder assessment. Personality disorders: toward theoretical and empirical inte- gration in diagnosis and assessment. In: $\mathrm{Ku}-$ prich SK. Personality disorders: Toward theoretical and empirical integration in diagnosis and assessment. Washington: American Psychological Association; 2015. p. 85-106.

33 McWilliams N. Beyond traits: personality as intersubjective themes. J Pers Assess. 2012; 94(6):563-70.

34 Herpertz SC, Huprich SK, Bohus M, Chanen A, Goodman M, Mehlum L, et al. The challenge of transforming the diagnostic system of personality disorders. J Pers Disord. 2017 Oct;31(5):577-89.

35 Weinberger DR, Glick ID, Klein DF. Whither Research Domain Criteria (RDoC)?: the good, the bad, and the ugly. JAMA Psychiatry. 2015 Dec;72(12):1161-2.

36 Glover NG, Crego C, Widiger TA. The clinical utility of the Five Factor Model of personality disorder. Pers Disord. 2012 Apr;3(2): 176-84.

37 Lowe JR, Widiger TA. Clinicians' judgments of clinical utility: a comparison of the DSMIV with dimensional models of general personality. J Pers Disord. 2009 Jun;23(3):21129.

38 Morey LC, Skodol AE, Oldham JM. Clinician judgments of clinical utility: A comparison of DSM-IV-TR personality disorders and the alternative model for DSM-5 personality disorders. J Abnorm Psychol. 2014 May;123(2): 398-405.

39 Samuel DB, Widiger TA. Clinicians' judgments of clinical utility: a comparison of the DSM-IV and five-factor models. J Abnorm Psychol. 2006 May;115(2):298-308.

40 Samuel DB, Widiger TA. Clinicians' use of personality disorder models within a particular treatment setting: A longitudinal comparison of temporal consistency and clinical utility. Pers Ment Health. 2011 Feb;5(1):12-28.

41 Chassan JB. On the development of clinical statistical systems for psychiatry. Biometrics. 1959;15(3):396-404.

42 Ringwald WR, Sharpe BM, Woods WC, Edershile EA, Wright AG. Psychopathology and personality functioning. In: Rauthmann JF, editor. Handbook of personality dynamics and processes. New York: Elsevier; forthcoming 2020.

43 Titchener EB. The postulates of a structural psychology. Philos Rev. 1898;7(5):449-65.

44 Hopwood CJ. Interpersonal dynamics in personality and personality disorders. Eur J Pers. 2018;32(5):499-524.

45 Hopwood CJ, Zimmermann J, Pincus AL, Krueger RF. Connecting personality structure and dynamics: towards a more evidencebased and clinically useful diagnostic scheme. J Pers Disord. 2015 Aug;29(4):431-48.

46 Hopwood CJ, Pincus AL, Wright AG. The interpersonal situation: Integrating clinical assessment, formulation, and intervention. In: Samuel D, Lynam D, editors. Using basic personality research to inform personality pathology. New York (NY): Oxford University Press; 2019. pp. 94-121. 
47 Pincus AL, Hopwood CJ, Wright AG. The interpersonal situation: An integrative framework for the study of personality, psychopathology, and psychotherapy. In: Funder D, Rauthmann JF, Sherman R, editors. Oxford handbook of psychological situations. New York: Oxford; forthcoming 2020.

48 Williams TF, Simms LJ. Th conceptual foundations of descriptive psychopathology. In: Wright AG, Hallquist MN, editors. Cambridge handbook of research methods in clinical psychology. New York (NY): Cambridge University Press; 2020. pp. 33-44.

49 Gore WL, Widiger TA. The DSM-5 dimensional trait model and five-factor models of general personality. J Abnorm Psychol. 2013 Aug;122(3):816-21.

50 Thomas KM, Yalch MM, Krueger RF, Wright AG, Markon KE, Hopwood CJ. The convergent structure of DSM-5 personality trait facets and five-factor model trait domains. Assessment. 2013 Jun;20(3):308-11.

51 Wiggins J. A psychological taxonomy of traitdescriptive terms: the interpersonal domain. J Pers Soc Psychol. 1979;37(3):395-412.

52 Conway CC, Forbes MK, Forbush KT, Fried EI, Hallquist MN, Kotov R, et al. A hierarchical taxonomy of psychopathology can transform mental health research. Perspect Psychol Sci. 2019 May;14(3):419-36.

53 Widiger TA, Sellbom M, Bach B, Chmielewski M, Clark LA, DeYoung CG, et al. Personality in a hierarchical model of psychopathology. Clin Psychol Sci. 2019 Jan;7(1):77-92.

54 Pincus AL, Lukowitsky MR, Wright AG, Eichler WC. The interpersonal nexus of persons, situations, and psychopathology. J Res Pers. 2009;43(2):264-5.

55 Fleeson W. Toward a structure- and processintegrated view of personality: traits as density distribution of states. J Pers Soc Psychol. 2001 Jun;80(6):1011-27.

56 Fleeson W, Gallagher P. The implications of Big Five standing for the distribution of trait manifestation in behavior: fifteen experiencesampling studies and a meta-analysis. J Pers Soc Psychol. 2009 Dec;97(6):1097-114.

57 Baumert A, Schmitt M, Perugini M, Johnson $\mathrm{W}$, Blum G, Borkenau P, et al. Integrating personality structure, personality process, and personality development. Eur J Pers. 2017; 31(5):503-28.
58 DeYoung CG. Cybernetic big five theory. J Res Pers. 2015;56:33-58.

59 Fleeson W, Jayawickreme E. Whole trait theory. J Res Pers. 2015 Jun;56:82-92.

60 Allport GW. Personality: A psychological interpretation. London: Holt; 1937.

61 Moskowitz D, Russell J, Sadikaj G, Sutton R. Measuring people intensively. Can Psychol. 2009;50(3):131-40.

62 Trull TJ, Ebner-Priemer U. Ambulatory assessment. Annu Rev Clin Psychol. 2013;9(1) 151-76.

63 Wright AG, Zimmermann J. Applied ambulatory assessment: integrating idiographic and nomothetic principles of measurement. Psychol Assess. 2019 Dec;31(12):1467-80.

64 Trull TJ, Ebner-Priemer UW. Ambulatory assessment in psychopathology research: A review of recommended reporting guidelines and current practices. J Abnorm Psychol. 2020 Jan;129(1):56-63.

65 Wright AG, Simms LJ. Stability and fluctuation of personality disorder features in daily life. J Abnorm Psychol. 2016 Jul;125(5):64156.

66 Russell JJ, Moskowitz DS, Zuroff DC, Sookman D, Paris J. Stability and variability of affective experience and interpersonal behavior in borderline personality disorder. J Abnorm Psychol. 2007 Aug;116(3):578-88.

67 Trull TJ, Solhan MB, Tragesser SL, Jahng S, Wood PK, Piasecki TM, et al. Affective instability: measuring a core feature of borderline personality disorder with ecological momentary assessment. J Abnorm Psychol. 2008 Aug;117(3):647-61.

68 Sadikaj G, Moskowitz DS, Russell JJ, Zuroff DC, Paris J. Quarrelsome behavior in borderline personality disorder: influence of behavioral and affective reactivity to perceptions of others. J Abnorm Psychol. 2013 Feb;122(1): 195-207.

69 Kaurin A, Beeney JE, Stepp SD, Scott LN, Woods WC, Pilkonis PA, Wright AGC. Attachment and borderline personality disorder: Differential effects on daily socio-affective processes. Forthcoming.

70 Wright AG, Stepp SD, Scott LN, Hallquist MN, Beeney JE, Lazarus SA, et al. The effect of pathological narcissism on interpersonal and affective processes in social interactions. J Abnorm Psychol. 2017 Oct;126(7):898-910.
71 Wright AG, Beltz AM, Gates KM, Molenaar PC, Simms LJ. Examining the dynamic structure of daily internalizing and externalizing behavior at multiple levels of analysis. Front Psychol. 2015 Dec;6:1914.

72 Wright AG. Moving from structure to function: Assessing a hierarchy of psychopathology in daily life. Paper presented as part of the symposium Novel Approaches to Explicating the Structure and Utility of Empirically Derived Structural Models of Psychopathology at the Annual Meeting for the Society for Research in Psychopathology. Buffalo; 2019.

73 Insel T, Cuthbert B, Garvey M, Heinssen R, Pine DS, Quinn K, et al. Research domain criteria (RDoC): toward a new classification framework for research on mental disorders. Am J Psychiatry. 2010 Jul;167(7):748-51.

74 Harkness AR, Reynolds SM, Lilienfeld SO. A review of systems for psychology and psychiatry: adaptive systems, personality psychopathology five (PSY-5), and the DSM-5. J Pers Assess. 2014;96(2):121-39.

75 DeYoung CG, Krueger RF. A cybernetic theory of psychopathology. Psychol Inq. 2018; 29(3):117-38.

76 Depue RA, Lenzenweger MF. A neurobehavioral dimensional model. In: Livesley WJ, editor. Handbook of personality disorders: Theory, research, and treatment. New York: Guilford Press; 2001. p. 136-76.

77 Depue RA, Lenzenweger MF. A neurobehavioral dimensional model of personality disturbance: Major theories of personality disorder. New York: Basic Books; 2005. p. 391-453.

78 Rosoff PM. Healthcare rationing cutoffs and Sorites indeterminacy. J Med Philos. 2019 Jul; 44(4):479-506.

79 Zachar P, McNally RJ. Vagueness, the sorites paradox, and posttraumatic stress disorder. In: Keil G, Keuck L, Hauswald R, editors. Vagueness in psychiatry. Oxford: Oxford University Press, 2017. p. 169-88.

80 Markon KE. How things fall apart: understanding the nature of internalizing through its relationship with impairment. J Abnorm Psychol. 2010 Aug;119(3):447-58.

81 Romanyshyn AT. Ontological classifications and human rationality in bioethics. J Med Philos. 2019 Aug;44(4):391-402.

82 Zachar P. Psychiatric disorders: natural kinds made by the world or practical kinds made by us? World Psychiatry. 2015 Oct;14(3):28890. 